\title{
A Poultry Farming Control System Using a ZigBee-based Wireless Sensor Network
}

\author{
Bilal Ghazal $^{1 *}$, Khaled Al-Khatib ${ }^{2 * *}$ and Khaled Chahine ${ }^{3 * * *}$ \\ ${ }^{1}$ Faculty of Sciences IV, Lebanese University (UL), Zahle, Lebanon \\ ${ }^{2}$ Faculty of Engineering, Lebanese International University (LIU), \\ Khyara, Lebanon \\ ${ }^{3}$ Faculty of Engineering, Beirut Arab University (BAU), Debbieh, Lebanon

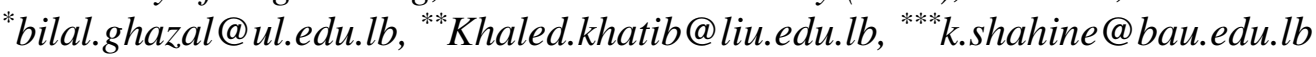

\begin{abstract}
Agriculture and poultry are the backbone of any country's economy. Indeed, there is a strong correlation between agricultural growth and economic prosperity. While poultry are raised for egg and meat production, farmers experience a huge financial loss because of inaccurate weather forecasts and ineffective methods employed in conventional farming. Therefore, new effective technological approaches are required to continuously improve the productivity, profitability, and sustainability of our major farming systems. A wireless sensor network (WSN) is proposed to monitor and measure many poultry environmental parameters such as temperature, humidity, air quality, and amount of light. The different sensors are disposed in particular positions in the farm in order to better reveal the realistic information. The collected farming data are sent by means of WSN via ZigBee transceivers to the main controller based on PIC microcontroller or PLC module. The main controller analyzes the various readings, compares them with the standard levels, evaluates the presented situations, considers the portfolio of foreseen cases, and finally gives the right instructions. In fact, the main microcontroller controls the corresponding equipment such as heater, cooler, fan and others according to the processed data. The proposed system design offers convenient directives for different facing scenarios and therefore enables all-weather real time control of the farming parameters and achieves a comfortable environment for the fowls.
\end{abstract}

Keywords: Smart farm; precision livestock farming; wireless sensor network; ZigBee; poultry automation system; henhouse environmental parameters

\section{Introduction}

Poultry farming includes all the processes of raising domesticated birds for the purpose of farming meat or eggs for food. Chickens, turkeys, ducks, pigeons and geese are among the most raised birds. Worldwide production of chickens has witnessed massive growth over the last 50 years to fulfill current worldwide consumer demands. As a matter of fact, poultry has dominated the meat's consumption in the United States, EU, and most other countries and has become the most dynamic animal product in the planet. Moreover, during the period between 2000 and 2012, the number of chickens consumed worldwide rose from 40.64 billion to 59.86 billion a year, whereas the average eviscerated weight per bird increased from $1.44 \mathrm{~kg}$ to $1.55 \mathrm{~kg}$ [1-2].

As stated by the Food and Agriculture Organization of the United Nations (FAO) [1], chickens are the most abundant domesticated birds and their meat constitutes approximately $88 \%$ of global poultry meat output. The 2015 production witnessed an increase of around 1 million tons in comparison with the 2014. According to FAO's

Received (November 11, 2016), Review Result (July 10, 2017), Accepted (August 8, 2017) 
expectations over the next years, by 2024 poultry meat's growth will be around $2.3 \%$ annually to reach 133 million tons, making it the largest meat sector from 2020 onward.

Despite the fact that the large scale commercial poultry production began in the $19^{\text {th }}$ century, poultry business is still revealing continuous increase in development and production due to the nature of the poultry's farming payback period, which is between 3 and 5 years. Currently, the poultry business became more ramified and may include egg production (layers breeding), meat production (broiler breeding), chicken breeding (hatchery), poultry equipment manufacturing, egg and meat processing, packaging, and finally poultry marketing and consultancy. However, the two dominant sectors of poultry industry are the layer chickens for high number of eggs where a production of 70 million tons of eggs are recorded in 2014 and the meat production often called broilers suitable for roasting, grilling, or barbecuing. The commercial broiler and layer markets produce more than 60 billion birds annually.

Many poultry farmers especially those involved in small-scale farming are performing the diverse operations manually. Thus, the farmers don't have the capability to realize the maximum benefits as confirmed by the economic feasibility. The rapid advances in technology perceived by the human society have greatly impacted the agricultural and farming sectors. In fact, the concept of smart farming has influenced several areas in both agriculture and poultry with the purpose of improving the productivity and environmental conditions. The increase in farms scale and the growth of raised animal numbers have dramatically enhanced the administrative, technical, organizational and logistic workload of the farmer. Therefore, it is indispensable to introduce the motivation of the precision livestock farming (PLF). PLF is based on the use of advanced technologies as integration among software, hardware, processes, and management to optimize the contribution of each animal. Consequently, the production facilities are running in an efficient and effective way in order to deliver better results with respect to quantity and quality.

The proposed system implements a Wireless Sensor Network (WSN) to acquire crucial environmental parameters such as temperature, humidity, air quality, and light intensity. The various sensors measure individually the appropriate parameters, and then the WSN collects the acquired readings and sends them to the master controller. The master controller is a processing and controlling unit that processes the input data to make the appropriate decisions ensuring the best suitable conditions for the birds. In fact, the master controller commands a set of electrical appliances, regulates the environment by optimizing the difference between the real collected data and the standard settings. Actually, the heater and the cooler and even the fan act on the temperature of the henhouse. The ventilation system regulates the humidity and the moisture, while the fanning system improves the air quality by providing an adequate supply of fresh air. On the other hand, the light controller unit selects the appropriate luminosity especially between day and night, makes dimming, and achieves the necessary on/off switching for different sources and sets off light in the farm. Moreover, many other appliances can be introduced in the system such as pumps for water supply and safe-lock mechanism for the ports and the gates of the farm. Furthermore, an automatic food feeder system, a camera monitoring system, a vaccination system, a smoke and a fire alarm system can all be introduced. However, a primary study is to be conducted to determine the right places inside the hencoop where the various kinds of sensors should be installed. This is due to the fact that some environmental parameters have different readings in different places according to the time of measurement, day-night, winter-summer and roof-ceil, and the effectiveness of the building insulation. The hardware design of the whole system and the programming code should be implemented in a way to ensure full communication between the wireless sensor network and the master controller, as well as between the master controller and the corresponding appliances. The performance superiority of the smart farm against the existing conventional one should motivate farmers to use technologies in their businesses. 


\section{Precision Livestock Farming (PLF)}

Incorporating technologies in any domain improves the quality of production, upgrades the process of functionalities, and enhances the quality assurance. Likewise, employing technology in poultry farming helps the farmers implement an overall quality and quantity management system. In fact, bird welfare depends on several environmental parameters that affect the revenue and the performance of the production such as laying time, egg weight, and average broiler weight. The henhouse must have the capability to measure, monitor, and control the temperature, humidity, moisture, ventilation, water intake, air quality, air speed and flow, heating system, $\mathrm{CO}_{2}$ and ammonia concentration, odor, light density and period of illumination, clean formulated feed, vaccination, and finally the optimal use of energy. When the environmental readings do not meet the standard levels, respiratory, digestive, and behavioral disorders probably take place. This reduces the food intake and may increase the rate of mortalities and likelihood of diseases.

In this work, we plan to construct a smart farm using wireless sensor network (WSN) based on ZigBee technology. The farm is supported by a network of smart sensors to measure in real time the environmental parameters of the henhouse as temperature, humidity, level of $\mathrm{CO}_{2}$, airflow speed, etc. Outdoor sensors could also be installed to study the effect of the weather on the indoor parameters. These sensors are connected to microcontrollers that are mounted by ZigBee transceivers for communication. A master controller receives the farming data sent by the sensors, compares it with the environmental standards, and analyzes it to understand the system interactions and status. Also, it develops accordingly command responses to the appropriate devices when the environmental measured values and the standard values do not match. Many controlled appliances are required in the farming such as heater, cooler, ventilation, water pump, door and window clocks, light switching and dimmers, sprinklers, feeder, and waste removal.

\section{Poultry Farming Houses Outlines}

The design of the poultry housing system is responsible for up to $40 \%$ of the rate of success that a farmer would achieve in the poultry business. The henhouse structure can have an open sided architecture dedicated for hot climates or be a windowless henhouse suitable for colder climates. It is not advisable to site the poultry farm within a residential area because of the offensive odor it produces. Bird droppings must be cleaned periodically either manually or automatically by a scraper.

The key features that need to be considered in designing a poultry building are: insulation of the wall and roof against high temperature in summer and cold temperature in winter, house design, location, and ventilation. Other features include roof color, pitch (quality of sound governed by the rate of vibration), orientation, and solar heat gain (can be built in shade). The dimensions of the henhouse should be long, wide and high with caged reared layers in case of egg production. Farmstead structure should be built at a particular angle by taking into consideration the sunset and the sunrise and by determining the direction of the prevailing winds.

Modern society is now more concerned with food safety and quality, efficient and sustainable animal farming, healthy animals, guaranteed animal welfare, and acceptable environmental impact of livestock production. Very few countries have regulations regarding broiler production, while other countries provide official recommendations. Starting from June 2010, new EU regulations (2007/4/EU) regarding minimum rules for the production of chickens kept for meat production are now required by the law [3]. Birds should be reared using a stocking density of approximately $33 \mathrm{~kg} / \mathrm{m}^{2}$ live weight under new EU guidelines on broiler welfare.

The next subsections mention the important environmental parameters linked to the farming process. For each parameter, the standard values are mentioned and the normal 
interval of operations is illustrated in order to be aware of the complexity of controlling a set of variable and dependent parameters. These parameters are related to the weather, season, time, outdoor climate, and the insulation of the building.

\subsection{Temperature}

The temperature of the henhouse should be 16 to $24^{\circ} \mathrm{C}$ [4-6]. At higher temperatures, the birds consume less food and convert the feed less efficiently. In colder environments, birds eat more feed to sustain normal body temperature. When bird feed is converted to heat energy by warmth, bird daily growth rate is reduced and mortality increases. It also leads to impaired immunity of the digestive system, increases the probability of contracting diseases, and reduces the overall poultry performance. However, the optimal temperature values depend also on the growing period of the broiler where each life period has an appropriate temperature.

\subsection{Humidity Levels}

The relative humidity for optimal growing is between 50\% and 70\% [7-9]. High relative humidity results in favorable conditions for microbial pollution growth in poultry litter, which increases the generation of ammonia $\left(\mathrm{NH}_{3}\right)$ and $\mathrm{CO}_{2}$. High $\mathrm{CO}_{2}$ levels lead to lethargic chicks with reduced weight gains, while high $\mathrm{NH}_{3}$ leads to poor feed conversions, reduced weight gains, and increased susceptibility to disease. Humidity is related to climate and its control processes in summer and winter are variable. However, the only practical technique to remove excess moisture from the henhouse is through ventilation where fan circulation should be optimized to achieve fresh air transport from outside to inside, from floor to ceiling, and from terminus to another.

\subsection{Air Quality}

The air quality is very crucial for the birds since bad air quality increases mortality rate $[6,10]$. The odors can be a combination of 60 to 150 different compounds: volatile fatty acids, mercaptans, esters, carbonyls, aldehydes, alcohols, ammonia, and amines. However, carbon dioxide and ammonia are the most important gases to measure. If the concentrations of these two gases are below recommended levels, then other gases are typically within recommended levels [15]. The upper critical level for ammonia is $20 \mathrm{ppm}$ (parts per million) while for $\mathrm{CO}_{2}$ is $2500 \mathrm{ppm}$. $\mathrm{CO}_{2}$ is produced by the breath of the birds themselves and by the gas heaters. $\mathrm{NH}_{3}$ is the result of the chemical reactions due to the decomposition and the fermentation of the litters and excrements inside the house. It is directly affected by the temperature, $\mathrm{pH}$, moisture, and nitrogen content of the litter.

\subsection{Fan and Air Flow}

The optimization of the farm ventilation achieves good air quality, influences temperature, reduces dust and ammonia levels, and controls humidity. Moreover, it can affect litter quality. The purposes of a well-designed ventilation system are to maintain an adequate supply of fresh air, remove excess moisture during cold weather, remove combustion gases from heaters, and provide adequate temperature control. So, fans and inlets must be designed to provide at least 3 phases of ventilation: lower continuous ventilation rate for winter, mild ventilation rate for temperature control during spring and fall, and maximum rate to limit the temperature rise in the summer.

The fan should be managed by an appropriate ventilation schedule. Ventilation rates are recommended to be of $0.15 \mathrm{~m} / \mathrm{s}$ for chicks under 7 days and $0.25 \mathrm{~m} / \mathrm{s}$ for others [6]. Also, the ventilation flow should be uniform in the house unless the birds migrate into better comfortable area where the overly crowded zone increases stress and mortality. 


\subsection{Water Intake}

The water is an important nutrient and the water intake is given to the birds by means of sprinklers. The amount of water depends on the age of chickens, temperature, humidity, airflow, and summer and winter seasons [11]. The water system must ensure adequate quantity and quality of water by controlling the operations of the pump supply, monitoring water volume, availability and levels, and by flowing regularly the required quantity of water through water lines, nipples and standpipes. The water system presents to the farmer numerous advantages: it provides fresh water clean of bacteria and harmful substances and it delivers vaccines, medications, and sanitation products.

\subsection{Farm Lighting}

Chicken is a long-day animal, which accepts light stimulation to eat nutrients at night and to continue the spawning process while an appropriate resting period each day is crucial. Several factors influence lights such as light intensity, photoperiod, light source, and wavelength [12]. During light period, the birds should be reared with an intensity of at least 20 lux and an illumination of at least $80 \%$ of the usable area. Light intensity should be less than 0.4 lux during the dark period. The light intensity improves health and provides normal behavior opportunities in comparison to the dim lighting. However, replacing older incandescent and tungsten halogen lights with newer LED smart lights can maximize illumination up to 10 times and save more than $40 \%$ of the energy.

\subsection{Locking Mechanism}

The automatic opening and closing of the doors, gates, and windows have similar technology but different purposes. The safe locking of outside gates of the farm permits a high level of security for the birds' healthcare. In fact, persons entering the farm should follow a certain sanitary process. Also, the farm can be supported by an auto-door opening system based on the time of the day and the level of authority of the workers.

However, for the buildings with open sided architecture, windows can be opened to provide a fresh supply of air. The opening period and the aperture dimension should be well defined.

\subsection{Video Monitoring}

The use of video surveillance achieves a real time monitoring for the poultry and allows a quick response for any abnormal conditions or severe problems. Moreover, modern digital image techniques can be used to assess the various activities of the birds, investigate the response of the birds to the indoor environment, locate and measure the relevant areas of the broilers, and estimate the live weight of the broilers.

On the other hand, the thermal imaging that uses the infrared thermography has been recently employed to study the birds' motion and to monitor the surface temperature giving evidence about the metabolic heat loss of chicken. Moreover, sophisticated algorithms can be applied to identify the dead birds and to detect the diseases especially the pathogenic avian influenza [18].

\section{Wireless Sensor Network (WSN)}

Many environmental and physical parameters like temperature, humidity, air quality and speed should be measured and controlled properly in the farm to accomplish allweather real time smart management and monitoring [9]. The conventional farm cannot regulate all these parameters, especially with the weather forecast. The automation planned to be implemented aims to control the environmental parameters of the henhouse in real time using wireless sensor network based on ZigBee technology. The farmer should be encouraged to adopt the smart farming system due to the direct impacts on the 
profits, business, and society [13-20]. WSN is a new technology that is implemented in various fields $[23,26]$. Recent applications cover the agriculture and farming sectors to optimize productivity and minimize cost [22]. The ZigBee technology [20, 22-25] is commonly used to achieve the communication between the various types of employed sensors and the master controller. ZigBee is a family of compatible radio modules based on the IEEE 802.15.4 standard designed for point-to-point and star communications. ZigBee transceivers allow for a very reliable, cost effective, and simple communication between the microcontrollers and are supported by sleep mode for extended battery life. The $1 \mathrm{~mW}$ ZigBee employed in this research work operates at $2.4 \mathrm{GHz}$ and has at least a range of $30 \mathrm{~m}$.

WSN offers a very convenient solution for data acquisition on animal welfare research. The full integration of WSN technology systems achieves low cost, real monitoring, reduction and simplification of wiring, lower installation and maintenance costs, easy replacement and upgrading of network, greater flexibility, and ability to organize and configure itself into an effective communication network. The farm house automation system based on ZigBee technology is designed to manage temperature, humidity and moisture, $\mathrm{CO}_{2}$, automatic lighting, climate control, fire and smoke detection, auto lock and release doors, feeder control, auto-sprinkler system, energy efficiency, and remote mobile connectivity.

It is important to select the best suitable scale for the environmental and physical parameters and the convenient sensors that should be implemented to measure the corresponding parameters. The hardware circuits required for each kind of sensors have to be designed in order to achieve a perfect communication using ZigBee between the network of smart sensors and the master controller. Next, the employed appliances such as heater, cooler, fan, and motor will be configured properly and controlled by the microcontroller. The system procedure aims to collect the farming data from sensors, send the data to the monitoring and control unit based on PIC microcontroller that analyzes it to understand the system interactions and status, and finally to develop control responses accordingly.

\section{Conclusion and Future Perspectives}

Precision livestock farming is the collection of data from animals and their environment by innovative, simple and low cost techniques then is followed by the evaluation of data using knowledge-based computer models. Thus, the automation system interprets the measurements, identifies the critical measurements, and performs the necessary adjustments. Precision livestock farming monitors in real time the birds' activities and allows adjusting the poultry house equipment including feeders, fans, heating systems, and sprinklers. The aim is to improve the birds' welfare, weights, growth, output of eggs, disease control, feed conversion and profit, and to monitor the animal behavior as well as microenvironment and emission of gaseous pollutants.

The architecture of the farming automation systems consists of different groups according to their functions and operations. The first set is formed of various sensors dedicated to measure the environmental parameters in the farm building as temperature, humidity, airflow, and others. The sensors are connected to a local control unit that acquires the readings and sends the data by means of ZigBee transceivers. The sensors group constitutes the WSN system. The main controller receives all the information, processes it, and responds according to predefined algorithms.

At the end, the benefits acquired for the whole system open the opportunities in the development of new electric devices, new hardware, new software applications, and new types of sensors for improving animal performance. 


\section{References}

[1] Food and Agriculture Organization of the United Nations. www.fao.org

[2] P. Smith, and C. Daniel. The chicken book, Athens, GA: The University of Georgia Press (2000)

[3] Council Directive 2007/43/EC. Laying down minimum rules for the protection of chicken kept for meat production, official journal of the European Union, 182/19, (2007) 28 June.

[4] H. Li, H. Wang, W. Yin, Y. Li, Y. Qian, and F. Hu. Development of a remote monitoring system for henhouse environment based on IoT Technology, Future Internet, (2015) Vol. 7, pp. 329-341.

[5] M. Bamhazi, H. Lehr et all. Precision livestock farming: an international review of scientific and commercial aspects, International journal of agricultural \& biological engineering, (2012) Vol. 5, No. 3, Sep.

[6] Q. Haixia, T. Banhazi, Z. zhigang, T. Low, and I. Brookshaw. Preliminary laboratory test on navigation accuracy of an autonomous robot for measuring air quality in livestock farming, International journal of agricultural \& biological engineering, (2012) Vol. 9, No. 2, March.

[7] A. Heber, J. Li, and T. Lim. Air quality measurements at a laying hen house: Experimental methods, International Symposium on control of gaseous and odour emissions from animal production facilities, Horsens, Denmark, (2003) June 2-4, pp. 161-171.

[8] N. Alloui, M. Alloui, O. Bennoune, and S. bouhentala. Effect of ventilation and atmospheric ammonia on the health and performance of broiler chickens in summer, Journal of World's poultry research, (2013) Vol 3, No. 2, pp. 54-56

[9] National agriculture advisor services NAADS. User guide on poultry rearing, (2011) Aug.

[10] N. Alloui, and A. Ayachi. Comparison of two control methods of decontamination in a poultry slaughter house, Journal of World's Poultry research, (2012) Vol. 1, No. 2, pp. 18-20.

[11] H. Han, and X. wang. A Network-based management information system for animal husbandry in Farms, International federation of information processing, (2010) pp. 49-54.

[12] J. Bang, I. Lee, M. Noh, J. Lim, and H. Oh. Design and implementation of a smart control system for poultry breeding's optimal LED environment, International journal of control and automation, (2014) Vol. 7, No. 2, pp. 99-108.

[13] A. Fanatico. Poultry house management for alternative production, National sustainable agriculture information service ATTRA, (2007).

[14] S. Wu, K. Wu, J. Liang, Z. Li, and P. Yang. Design of remote environment control system of intelligent network house based on ARM9, Procedia Engineering, (2011) Vol. 15. pp. 1056-1060.

[15] G. Corkery, S. Ward, C. Kenny, and P. Hemmingway. Incorporating smart sensing technologies into the poultry industry, Journal of World's poultry research, (2013) Vol 3, No. 4, pp. 106-128.

[16] S. Goud, and A. Sudharson. Internet based smart poultry farm, Indian journal of science and technology, (2015) Vol. 8, No. 19, Aug.

[17] R. Muttha, S. Deshpande, M. Chaudhari, and N. Wagh. PLC based poultry automation system, International journal of scientific research, (2014) Vol. 3, Issue 6, June.

[18] S. So-In, S. Poolsanguan et all. Smart mobile poultry farming systems in Tmote sky WSNs, International journal of digital content technology and its applications (JDCTA), (2013) Vol. 7, No. 9, May.

[19] D. Kanjilal, D. Singh, R. Reddy, and J. Mathew. Smart farm: Extending automation to the farm level, International journal of scientific \& technology research, (2014) Vol. 3, Issue 7, July.

[20] L. Garcia, L. Lunadei, P. Barreiro, and J. Robla. A review of wireless sensor technologies and applications in agriculture and food industry: state of the art and current trends, Sensors, (2009) Vol. 9, pp. 4728-4750.

[21] F. Dong, and N. Zhang. Wireless sensor network applied on environmental monitoring in fowl farm, International federation of information processing, (2010) pp. 579-486.

[22] L. Ma, J. Yan, S. Yan, B. Wang, K. Liao, and J. Wang. A study of agriculture meteorological monitoring system based on wireless sensor networks, International journal of multimedia and ubiquitous engineering, (2014) Vol. 9, No. 7, pp. 15-26.

[23] A. Dhivia, J. Infanta, and K. Chakrapani. Automated agriculture process using PLC and ZigBee, Journal of artificial intelligence, (2012) Vol. 5, No. 4, pp. 170-177.

[24] C. Chavan, and P. Karande. Wireless monitoring of soil moisture, temperature \& humidity using ZigBee in agriculture, International journal of engineering trends and technology, (2014) Vol. 11, No. 11, May.

[25] N. Pateh, H. Kathiriya, A. Bavarva. Wireless sensor network using Zigbee, International journal of research in engineering and technology, (2013) Vol. 2, Issue 6, Jun. 


\section{Authors}

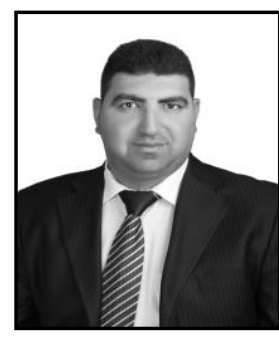

Bilal Ghazal, he received his Diploma in Electrical and Electronics Engineering in 2007 from the Lebanese University Faculty of Engineering III, Beirut, Lebanon. He received his Ph.D degree from Claude Bernard University, Lyon France in 2009. Bilal Ghazal is presently working as assistant professor in the Faculty of Sciences VI, Lebanese University, Lebanon. His area of interest is Microcontrollers, Home Automation, Control System, Robotics, and Image Processing.

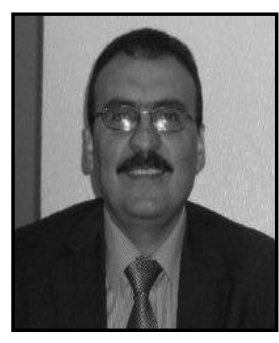

Khaled Al-Khatib, he received his B.E. in Electrical Engineering, section of Electrical Communications and Electronics in 1993 from the Beirut Arab University. He received his Master of Communication Engineering degree from the Beirut Arab University, Beirut, Lebanon in 2010. Khaled Al-Khatib is working since 2004 as Laboratory Instructor in the School of Engineering, Lebanese International University, Lebanon. His area of interest is Microcontrollers, Electrical and Electronic systems, Communications and Antenna, and Signal Processing.

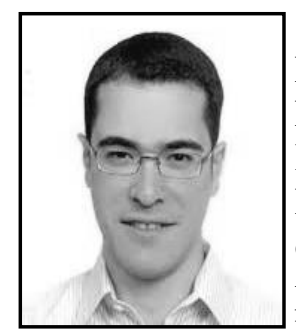

Khaled Chahine, he received his B.E. in Electrical and Electronics Engineering from the Lebanese University, Beirut, Lebanon, in 2007, his M.S. in Electronic Systems and Electrical Engineering from Polytech'Nantes, Nantes, France, in 2007, and his Ph.D. in Electrical and Electronics Engineering from the University of Nantes, Nantes, France, in 2010. In 2010, Dr. Chahine was a postdoctoral researcher with LASMEA laboratory, Blaise Pascal University, Clermont-Ferrand, France. From 2011 to 2016, he was an assistant professor with the Department of Electrical and Electronics Engineering of the Lebanese International University, Beirut, Lebanon. Since September 2016, he has been an assistant professor with the Electrical and Computer Engineering Department of Beirut Arab University, Debbieh campus, Lebanon. His research interests include statistical signal processing, control systems, nondestructive testing and evaluation, and non-intrusive appliance load monitoring. 